\title{
Spontaneous Telepathy and the Problem of Survival ${ }^{1}$
}

\author{
Gardner Murphy \\ College of the City of New York
}

Some 35 years ago I took into my employment a tender, delicate-looking boy, Robert Mackenzie, who, after some three or four years' service, suddenly left. .. A few years afterwards, my eye was caught by a youth of some 18 years of age ravenously devouring a piece of dry bread on the public street, and bearing all the appearance of being in a chronic state of starvation. Fancying I knew his features, I asked if his name were not Mackenzie. He at once became much excited, addressed me by name, and informed me that he had no employment; that his father and mother, who formerly supported him, were now both inmates of the "poorhouse," to which he himself had no claim for admission, being young and without any bodily disqualification for work, and that he was literally homeless and starving. ... Suffice it to say that he resumed his work, and that, under the cirumstances, I did everything in my power to facilitate his progress. . I was apparently his sole thought and consideration, saving the more common concerns of daily life.

In 1862 I settled in London, and have never been in Glasgow since. Robert Mackenzie, and my workmen generally, gradually lost their individuality in my recollection. About 10 to 12 years ago my employés had their annual soirée and ball. This was always held ... on a Friday evening .... On the Tuesday morning following, immediately before 8 A. M., in my house on Campden Hill, I had the following manifestation, I cannot call it a dream; but let me use the common phraseology. I dreamt, but with no vagueness as in common dreams, no blurring of outline or rapid passages from one thing disconnectedly to another, that I was seated at a desk, engaged in a business conversation with an unknown gentleman, who stood on my right hand. Towards me, in front, advanced Robert Mackenzie, and, feeling annoyed, I addressed him with some asperity, asking him if he did not see that I was engaged. He retired a short distance with exceeding reluctance, turned again to approach me, as if most desirous for an immediate colloquy, when I spoke to him still more sharply as to his want of manners. On this, the person with whom I was conversing took his leave, and Mackenzie once more came forward. "What is all this, Robert?" I asked, somewhat angrily. "Did you not see I was engaged?" "Yes, sir," he replied; "but I must speak with you at once." "What about?" I said; "what is it that can be so important?" "I wish to tell you, sir," he answered; "that I am accused of doing a thing I did not do, and that I want you to know it, and to tell you so, and that you are to forgive me for what I am blamed for, because I am innocent." Then, "I did not do the thing they say I did." I said, "What?" getting same answer. I then naturally asked, "But how can I forgive you if you do not tell me what you are accused of?" I can never forget the emphatic manner of his answer, in the Scottish dialect, "Ye'll sune ken" (you'll soon know). This question and the answer

1 [Originally published in JP, 1943, 7, 50-60.] 
were repeated at least twice-I am certain the answer was repeated thrice, in the most fervid tone. On that I awoke, and was in that state of surprise and bewilderment which such a remarkable dream, quâ mere dream, might induce, and was wondering what it all meant, when my wife burst into my bedroom, much excited, and holding an open letter in her hand, exclaimed, "Oh, James, here's a terrible end to the workmen's ball, Robert Mackenzie has committed suicide!" With now a full conviction of the meaning of the vision, I at once quietly and firmly said, "No, he has not committed suicide." "How can you possibly know that?" "Because he has just been here to tell me."

I have purposely not mentioned in its proper place, so as not to break the narravive, that on looking at Mackenzie I was struck by the peculiar appearance of his countenance. It was of an indescribable bluish-pale colour, and on his forehead appeared spots which seemed like blots of sweat. For this I could not account, but by the following post my manager informed me that he was wrong in writing of suicide. That, on Saturday night, Mackenzie, on going home, had lifted a small black bottle containing aqua fortis (which he used for staining the wood of birdcages, made for amusement), believing this to be whisky, and pouring out a wineglassful, had drunk it off at a gulp, dying on the Sunday in great agony. Here, then, was the solution of his being innocent of what he was accused of- suicide, seeing that he had inadvertently drunk aqua fortis, a deadly poison. Still pondering upon the peculiar colour of his countenance, it struck me to consult some authorities on the symptoms of poisoning by aqua fortis, and in $\mathrm{Mr}$. J. $\mathrm{H}$. Walsh's "Domestic Medicine and Surgery," p. 172, I found these words under symptoms of poisoning by sulphuric acid ... "the skin covered with a cold sweat; countenance livid and expressive of dreadful suffering." ... "Aqua fortis produces the same effect as sulphuric, the only difference being that the external stains, if any, are yellow instead of brown." This refers to indication of sulphuric acid, "generally outside of the mouth, in the shape of brown spots." Having no desire to accommodate my facts to this scientific description, I give the quotations freely, only, at the same time, stating that previously to reading the passage in Mr. Walsh's book, I had not the slightest knowledge of these symptoms, and I consider that they agree fairly and sufficiently with what I saw....

My manager first heard of the death on the Monday-wrote me on that day as above-and on the Tuesday morning, immediately before the 8 A.M. post delivery, hence the thrice emphatic "Ye'll sune ken." I attribute the whole to Mackenzie's yearning gratitude for being rescued from a deplorable state of starvation, and his earnest desire to stand well in my opinion. I have coloured nothing, and leave my readers to draw their own conclusions ${ }^{2}$

Thus years after the last contact between Robert Mackenzie and his employer, an agonized dream told the latter that Mackenzie was not guilty of a charge against him. The apparition came from nowhere, was apparently suggested by nothing, announced itself with horrible but heroic intensity; the employer would soon know the full authenticity of the dream message.

This is one of a heap of investigated spontaneous cases in which the percipient is not, like an ESP subject, searching, reaching out towards a goal; there is no effort of the percipient to make contact with a specific distant event. Rather, an impluse comes forcing its way through into the percipient's experience. What do such happenings mean? 


\section{"ACTIVE AND PASSIVE TELEPATHY"}

First, is this ESP as we know it? Of course it will be ESP if one stretches that term to include the entire sphere of the mental phenomena of psychical research. There is, however, no clear evidence that any of the ESP data with which the laboratory is concerned involve a dynamic forcing of an agent's way into the unsuspecting mentality of a percipient who is in no way concerned to make supernormal contact. But there are many spontaneous cases of this type. And there are many "semi-experimental" cases in which the agent's effort to transmit something impresses itself successfully on an unprepared percipient ${ }^{4}$, as when my friend E. L. Cox gave mental orders which were minutely fulfilled by a friend at a distance. ${ }^{5}$

\section{APPARITIONS OF THE DECEASED}

It must, I think, be granted that active telepathy is the basis of most of the spontaneous cases.

But whose activity is it? That of a living person's mind, or that of the mind of a person deceased? The answer lies partly in a study of the time-relations of death and apparition.

It has long been known that apparitions are especially likely to occur at about the time of the agent's death; indeed, the statistical treatment afforded in Phantasms of the Living indicated a very large number within twelve hours of the death (the percipient not knowing that the agent was ill or in danger), and Myers schematically indicated the time-relations (shown in Figure I) in which there is a tapering-off of evidential cases as the days pass after death. ${ }^{6}$ Most psychical researchers have always been inclined to attribute cases appearing soon after death to "latency" in the mind of the percipient; i.e., they have postulated that in apparitions of the deceased the impression was actually received during the last moments of the agent's life, emerging later in the percipient's experience.

3 This terminology is borrowed from R. Warcollier, Experimenal Telepathy (Boston, 1938), p. 93.

4 E. Gurney, F. W. H. Myers, F. Podmore, Phantasms of the Living (London: Trüber and Co., 1886), I, 104 ff.

5 C. Murchison (Ed.) The Case For and Against Psychical Belief (Worcester: Clark University, 1927) p. 272.

6 See Proc. S. P. R., V (1888-89), 427. 


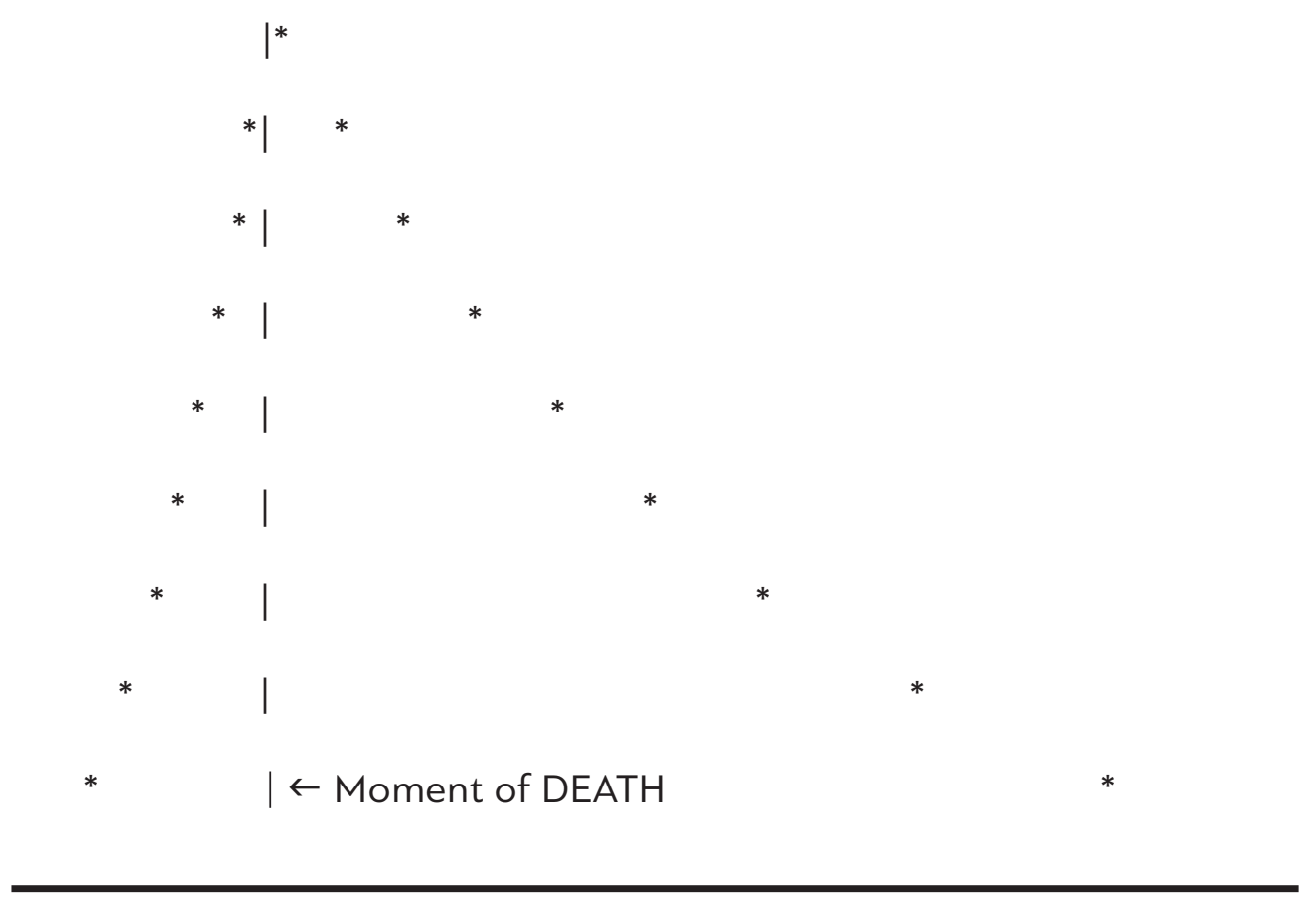

ONE WEEK

ONE YEAR

Fig. I

But what shall we do with apparitions which appear months or years or more after death, the death being unknown to the percipient?

The following is a run-of-the-mill sample:

V.---From Mr. John E. Husbands, of Melbourne House, Town Hallsquare, Grimsby.

September $15^{\text {th }}, 1886$.

Dear Sir:---The facts are simply these. I was sleeping in a hotel in Madeira in January, 1885. It was a bright moonlight night. The windows were open and the blinds up. I felt some one was in my room. On opening my eyes I saw a young fellow about 25 , dressed in flannels, standing at the side of my bed and pointing with the first finger of his right hand to the place I was lying. I lay for some seconds to convince myself of some one being really there. I then sat up and looked at him. I saw his features so plainly that I recognized them in a photograph which was shown me some days after. I asked him what he wanted; he did not speak, but his eyes and hand seemed to tell me I was in his place. As he did not answer, I struck out at him with my fist as I sat up, but did not reach him, and as I was going to spring out of bed he slowly vanished through the door, which was shut, keeping his eyes upon me all the time.

Upon inquiry I found that the young fellow who appeared to me died in that room I was occupying. 
If I can tell you anything more I shall be glad to, if it interests you.

JOHN E. HUSBANDS.

The following letters are from Miss Falkner, of Church-terrace, Wisbech, who was resident at the hotel when the above incident happened.

October 8th, 1886.

The figure that Mr. Husbands saw while in Madeira was that of a young fellow who died unexpectedly months previously, in the room which Mr. Husbands was occupying. Curiously enough, Mr. H. had never heard of him or his death. He told me the story the morning after he had seen the figure, and I recognized the young fellow from the description. It impressed me very much, but I did not mention it to him or anyone. I loitered about until I heard Mr. Husbands tell the same tale to my brother; we left Mr. H. and said simultaneously "He has see Mr. D."

No more was said on the subject for days; then I abruptly showed the photograph.

Mr. Husbands said at once, "That is the young fellow who appeared to me the other night, but he was dressed differently"---describing a dress he often wore- "cricket suit (or tennis) fastened at the neck with sailor knot." I must say that that Mr. Husbands is a most practical man, and the very last one would expect "a spirit' to visit.

\section{K. FALKNER.}

October 20th, 1886.

I enclose you photograph and an extract from my sister-in-law's letter, which I received this morning, as it will verify my statement. Mr. Husbands saw the figure either the 3rd or 4th of February, 1885.

The people who had occupied the rooms had never told us if they had seen anything, so we may conclude they had not.

\section{K. FALKNER.}

The following is Miss Falkner's copy of the passage in the letter: 
You will see at back of Mr. DuF-------'s photo the date of his decease (January 29th, 1884); and if you recollect "the Motta Marques" had his rooms from the February till the May or June of 1884, then Major Money at the commencement of 1885 season. Mr. Husbands had to take the room on February 2nd, 1885, as his was wanted.

I am clear on all this, and remember his telling me the incident when he came to see my baby. ${ }^{7}$

The question confronts us: who, or what initiated this experience? The dreamer's mind? Some distant living person? The deceased?

I venture that many readers will intuitively assign to the deceased the activity which is the source of the impression without thereby asserting that the apparition necessarily is the deceased; F. C. S. Schiller beautifully expressed this hypothesis by saying that apparitions are the "dreams of the dead." At any rate we must press the question: if the receiving of a clear and strong, though unexpected message-a hammer-blow dealt to one's unsuspecting mind-indicates more than passive percipiency, namely a real activity by an agent, is there any real basis for interpreting messages from the living as real messages, while at the same moment forcing all messages from the deceased into the procrustean bed of "ESP," assigning all the roles in the drama to a living percipient, who "does all the work"? When, in the "Chaffin Will" case ${ }^{8,}$ an insistent dream message purporting to come from the dreamer's father directs the dreamer to the discovery of an unknown will, which is accepted as valid by all who knew the testator, is this simply clairvoyance of the will? Perhaps so. But what initiated the process?

When Miss R. C. Morton ${ }^{9}$ became intrigued by the frequent appearance of a phantasm which walked about the house, making itself visible to several members of the family, and to two neighbors who saw it near the house, she set herself the task of recording its appearances and disappearances, pursued it into corners until it disappeared; tried to make it turn and directly confront her; and, driven to sterner methods, attached a string with glue to the wall by the staircase, stood at the foot of the stairs and watched it walk down through the string.

Now there is some ESP in this case, in the sense that there is an unexplained correspondence between the times and places upon which the phantasm is observed by the different individuals, not all of whom are in normal communication with one another; and there may be a certain retrocognitive clairvoyance in the fact that the form and behavior of the phantasmal woman seem to correspond with the appearance and form of a woman who had earlier lived in the house. The main interest of the case, however, lies not in these details, but in the initiative taken, so to speak, by the phantasm. Miss Morton and her relatives and neighbors are not engaged in telepathic experiments, even in the broader sense of the word. They are not, at the beginning of these experiences, interested in the deceased individual whom the phantasm seems to portray. Whatever it is that initiates the experience, as in the Mackenzie case, comes from outside, bursts through the ordinary barriers of experience and compels the attention of the living.

7 lbid., 416-417.

8 Ibid.,XXXVI (1928), 517-524.

9 Ibid., VIII (1892), 311-312. 


\section{THE “EXTENDED TELEPATHY” HYPOTHESIS vs. THE SURVIVAL HYPOTHESIS}

From the very beginning of psychical research, cases of this type were a center of controversy between (1) those who wished to expand the hypothesis of telepathy to cover all instances of supernormal awareness, and (2) those who wished to distinguish between cases of active percipiency, the quest of an individual for specified supernormal information, and passive percipiency, in which the percipient is merely the receiving station for something initiated from outside his personality. The second group of researchers were interested in determining who were the active agents.

Now as far as I know, there was never any doubt that the latter group had the better of the argument as far as actual evidence was concerned. The basis of argumentation by the former group of investigators was frankly the hope that telepathy could be so defined as to permit evasion of the survival hypothesis. Gurney, who had his hands full establishing telepathy, was in no way anxious to run full tilt into all the difficulties of the survival question, while Podmore, in the same period, and more and more insistently as time went on, made it his special task to stretch telepathy in every conceivable dimension, with the professed purpose of making the survival hypothesis unnecessary. Followers of Podmore convinced themselves that if we once accept the capacity of the individual living mind to make contact with the past or present thoughts or feelings of other living persons, sometimes catching the thought as it develops, some times becoming aware of it after a period in which it has lain dormant in the receiver's subconscious, it will be impossible for any deceased mind, if it exists to demonstrate its continuation beyond death. Myers, on the contrary, early became convinced that this argument was forced and inconsistent; that apparitions behaved autonomously in terms of their own dynamics, not primarily in terms of the dynamics of the percipient; that they came when least expected or wanted, that they appeared to those who had never known them, and that under certain special conditions they could overwhelm the percipient even to the point of "invasion" of his experience, blotting out all competing experiences, momentarily reconstituting psychological space in which he lived ${ }^{10}$

Thus in many of the best cases of "invasion" described in Phantasms of the Living the invading presence transforms the world around the percipient, while indeed in several such cases the distant agent, in coma or dream, indicates to those nearby that he is in fact invading the region now occupied by the percipient. Since all this can be established clearly enough, Myers argues that the transmission of telepathic impulses from the living and from the deceased follows the same principle; the invasion experiences express the same dynamics whether the apparition is that of a living or that of a deceased person.

A defender of the ESP hypothesis might reply: To be sure, there is a great deal of difference between looking for something and having it thrust upon us; between listening for something and having it obtrude itself noisily upon our ears. No psychologist in his right mind would apply the terminology of the former cases to clear-cut instances of the latter. All of these, to be sure, are instances of "perception"; but the stimulus, in the one case, lies near at hand and is sought, while in the other case, the stimulus, which may happen to be another human personality, comes to meet the perceiver and, if need be, may overpower him as a thunderclap does. Students of ESP are concerned as much with agency as with percipiency.

10 Cf. especially E. Gurney er al., op. cit., II, 277-316. 
So far so good. But does this admission carry us far enough? The essential thing, Myers would argue, is the motivation. Thus Mackenzie's employer had only a casual, albeit friendly, memory of his former employee. The dramatization of his suicide serves no great personal aim for the percipient. For Mackenzie, however, the rigor of Scottish Calvinist ethics makes suicide an unbearable burden to contemplate, and nothing would be more reasonable than for the dying man to wish fervently to absolve himself of guilt. If Mackenzie and the scores of others who have appeared hours, months or years after death no longer exist, what supplies the motivation?

Here we have clearly come to the definition of two basic differences between the thinking of Podmore and of Myers: (1) Myers is profoundly concerned with motives, Podmore is not; (2) Myers, but not Podmore, distinguishes between the two types of percipiency-active and passive. With Myers we are concerned with the interaction between the subliminal selves of two individuals, the agent being as important in the process as the percipient. For Podmore the living percipient, who is the real subject in telepathy, the person "who does the work," is endowed also with the capacity to simulate and dramatically elaborate the action, speech and purpose of the agent, even to the point of producing a complete phantasm. Thus Mackenzie's employer, paranormally perceiving the fact of Mackenzie's death and circumstances attending it, re-works the material in a dream some hours later and produces it as a message from the deceased, while Miss Morton and her fellow witnesses, paranormally perceiving a few facts about an earlier dweller in the house, project the facts in personal form into a very lively, spontaneous, and unpredictable ghost.

Now there is nothing psychologically impossible about this last group of hypotheses. But they are hypotheses supported by incomplete evidence, adduced partly for the avowed purpose of avoiding direct confrontation of the survival question. Myers clearly saw this, and hammered away at the point for nearly twenty years. This is not equivalent to our saying that he necessarily had the better of the argument; the issue is incredibly complicated and the limits of extra-sensory capacity can certainly not be set. One thing, however, can be said: experimental telepathy and clairvoyance, as we know them, do not cover by any means the chief established facts about apparitions, and it is wishful thinking to extend any hypothesis of this type to events of which we know so little.

And let us repeat: the most serious bungling involved in attempting the stretching of hypotheses in this way is the neglect of motivation. Motives are something which the psychologist never has a right to evade. The spontaneous cases are shot through and through with compelling evidence of powerful motivation. Most of the spontaneous cases have to do with death, illness or catastrophe; they come to those who are near and dear to those involved. Motivation is present in both agent and percipient in most cases. When, however, the percipient has no such motivation, is not oriented to the agent nor concerned with what is happening to him, and the impulse compels the attention of the percipient willy-nilly, our obligation is just as clear to look elsewhere for motivation processes; and if they exist they must be assigned to the agent. If the agent is living, this fact by itself greatly extends what we call the ESP process. But if the agent is deceased this makes more demands upon us. Somewhere beyond our ordinary time and space, a motivation process deflects the living from their ordinary concerns, twists and wrenches them from their usual preoccupations, lifts them into a timespace experience with a full motivational richness which belongs to the deceased. This is the empirical situation with which ESP investigators and all psychical researchers must honestly deal. 
In any era of active experimental research in any science, the great problem is to keep investigators looking at the things that Nature throws at them, rather than only at their own little pile of halfsolved problems, half-perfected tools. When Newton's followers got the mechanics of the Universe, and its ways of demonstrating its laws, all settled, it was hard for Nature to make herself heard through the contented buzz of the scientists; when experimental psychology got itself nicely organized for the study of perception it was hard to get investigators to listen to the plain fact that perception expresses the deep dynamics of individual personality. And when ESP research got nicely organized, many of its laboratory investigators tended to forget that Nature constantly throws at us a baffling problem, that of apparitions of the deceased, which need more study both to teach us the difference between active and passive telepathy and to lead us to inquire why personality continues somehow to intrude itself into the experience of others beyond the time of the death of the organism.

I have not meant to imply in any way that apparition are a proof of survival, nor even that they are necessarily "better evidence" for survival than are the Piper or Leonard type of communications or the cross-correspondences. But I do mean to emphasize two points: first, that as long as they suggest post-mortem continuity of personality, and are only with difficulty treated as cases of ESP, they should be fearlessly studied in the light of the survival hypothesis; second, that whether the answer to the survival question is ultimately yes or no, the study of the origins of apparitions will add enormously to our understanding of the telepathic processes-their structure, extent and significance. 